\title{
OXIDATIVE HEMOLYSIS AND PRECIPITATION OF HEMOGLOBIN. I. HEINZ BODY ANEMIAS AS AN ACCELERATION OF RED CELL AGING*
}

\author{
By JAMES H. JANDL, LOUISE K. ENGLE and DAVID W. ALLEN \\ (From the Thorndike Memorial Laboratory and Second and Fourth (Harvard) Medical \\ Services, Boston City Hospital, and the Department of Medicine, Harvard \\ Medical School, Boston, Mass.)
}

(Submitted for publication June 28, 1960; accepted July 21, 1960)

The propensity of certain chemicals and drugs to induce hemolytic anemias has been a subject of much interest for almost a century (1-4). The majority of substances so active are aromatic compounds containing amino-, nitro-, or hydroxy groups, although a number of inorganic compounds (e.g., hydroxylamines, nitrates, nitrites and chlorates) are also active (1-4). Such compounds usually cause red cell injury without evidence of specific toxicity to other cells or tissues. The hemolytic process is characterized by two rather distinctive features in the affected red cells : 1) the appearance of brownish or greenish derivatives of hemoglobin, including methemoglobin, according to most (3) but not all (4) reports; and 2) the formation within red cells of water-insoluble, stainable granules, generally termed Heinz bodies.

There has been extensive debate as to the identity and significance of the hemoglobin discoloration following the administration of these compounds. Much of the disagreement may be attributed to the fact that many of the observations have been made in vivo, where pigments initially produced by the compound are mixed with the various products of hemoglobin catabolism. Furthermore, the fact that certain of the pigments produced, such as methemoglobin, are reversible, whereas certain others (including so-called sulfhemoglobin) are not (3), has undoubtedly led to conflicting observations. In those few studies where early, sequential observations have been made, methemoglobinemia has been striking albeit transient $(5,6)$. Studies of compounds such as phenylhydrazine, which are active against red cells in vitro as well as in vivo, have shown that hemoglobin may be changed in part to methemo-

* This investigation was supported in part by Grant no. RG3507 (C8) from the National Institutes of Health, Bethesda, Md. globin and in part to brown or green pigments, some of which are insoluble $(7,8)$, and which include the hemochromes, sulfhemoglobin $(3,7)$, verdoglobin $(7,9,10)$, and choleglobin $(3,11)$. These pigments are not well defined chemically and may be considered collectively as various forms of irreversibly denatured hemoglobin with heightened absorption of red light.

An even more voluminous and conflicting body of literature has arisen concerning the nature of the Heinz body $(1,2)$. The most prevalent of many views has been that Heinz bodies consist, at least in part, of particles of denatured protein (1) and these are presumed to include denatured globin (2). Indeed, denatured globin has been identified in the blood of animals with Heinz body anemias $(10,12)$ and Heinz bodies have been found to have the staining properties of globin rather than of stromal protein (8). However, studies by electron microscopy were interpreted by one observer to indicate that these inclusions were derived from denatured stromal protein (13), while others concluded that the particles derived from affected blood were too opaque to be denatured protein (14).

A third less specific and possibly less constant feature of the Heinz body anemias is the appearance of spherocytosis and increased osmotic fragility $(15,16)$. As with the methemoglobinemia, conflicting reports as to the occurrence or absence of spherocytosis may be in part attributed to mechanisms in vivo, such as splenic filtration, which would tend to eliminate spherocytes from the blood stream. Many of these compounds which produce methemoglobin and Heinz bodies in vitro also cause spherocytosis and increased osmotic fragility in vitro, which usually become apparent only after several hours $(15,17)$.

The injurious effects of the hemolytic drugs in vivo and in vitro are modified by the character 
of the red cells involved. Thus, red cells of some species, such as the cat, are more susceptible to injury in terms of methemoglobin formation as well as of hemolysis in vivo and in vitro. (17) than those of other species. Old red cells are more susceptible than young $(16,18)$. The red cells of some individuals, particularly certain Negroes and dark-skinned Caucasians (19), are more susceptible than those of most individuals. The mechanism of individual hypersusceptibility ${ }^{1}$ has been well characterized in recent years (19), and apparently depends upon an inborn, geneticallydetermined metabolic error resulting in a deficiency of the enzyme glucose-6-phosphate dehydrogenase (20). This enzyme catalyzes the first step of the pentose phosphate pathway which provides the mature red cell with its only oxidative apparatus and which is responsible for the generation of reduced triphosphopyridine nucleotide $(\mathrm{TPNH})$. TPNH, in turn, is possibly involved along with DPNH (21) in the enzymatic reduction of methemoglobin (22) and of oxidized glutathione (GSSG) $(23,24)$. Since reduced glutathione (GSH) levels in the red cells of hypersusceptible individuals tend to be low and to fall more rapidly than normal in the presence of the hemolytic compounds (19), and since glucosedeficient normal red cells are also "hypersusceptible" (19), it is generally accepted that oxidative glycolysis provides a cellular defense against these drugs, possibly through the preservation or regeneration of GSH. Normal red cells become hypersusceptible in the same sense as they grow old, for they too are deficient in glucose-6-phosphate dehydrogenase (25) and thereby manifest "glutathione instability" (19).

Whether or not GSH per se is protective to the drug-exposed red cell, and, if so, in what way, is not clear. GSH levels and "GSH stability tests" on the red cells of hypersusceptible individuals do not appear to correlate with the marked differences in susceptibility occurring before and after drug exposure (26). Furthermore, the fate of

1 The expressions "sensitive" or "insensitive" in regard to the red cells of subjects with glucose-6-phosphate dehydrogenase deficiency, and normal subjects, respectively, may be objected to as suggesting an all-or-none relationship which obscures the fact that all individuals are in some degree susceptible to toxic hemolysis by this family of drugs and chemicals.
GSH in drug-exposed red cells is unknown; it is clear from inspection of the in vitro data of Beutler, Robson and Buttenwieser (27) and from in vivo studies (26), that GSH is not simply oxidized to GSSG. Finally, there are certain unexplained differences after drug exposure in the pattern of hemolysis and in the appearance of the Heinz bodies in the hypersusceptible individual as compared to the normal.

The following studies, presented in preliminary form elsewhere (28), were made in an effort to understand the actual mechanism by which the hemolytic compounds cited cause cellular injury and to explain some of the manifestations of this injury. The present report is concerned with the sequence of changes during the degradation of hemoglobin by these compounds, their mechanism of action, and the relation of Heinz body anemias to normal cellular aging. A second paper will present studies of the relation of thiols to the destruction of hemoglobin and of red cells by these hemolytic agents.

\section{MATERIALS AND METHODS}

Red cells derived from fresh defibrinated human blood were washed three times in 10 to 20 volumes of cold physiological ("isotonic") saline and then prepared as 50 per cent suspensions in isotonic phosphate buffer, $\mathrm{pH}$ 7.4. Human hemoglobin for most studies was prepared from red cells washed five times at $0^{\circ} \mathrm{C}$ in isotonic saline and hemolyzed at $0^{\circ} \mathrm{C}$ with 1.5 volumes of water and 0.4 volume of toluene. Subsequently sufficient sodium chloride was added to bring its concentration to $0.16 \mathrm{M}$ and the hemolysate was centrifuged at $0^{\circ} \mathrm{C}$ for 1 hour at about $1,000 \mathrm{G}$. The clear hemolysate was withdrawn and dialyzed for approximately 48 hours at $4^{\circ} \mathrm{C}$ against $2.8 \mathrm{M}$ phosphate buffer, $\mathrm{pH} 6.8$, according to the procedure of Drabkin (29) for preparing crystalline hemoglobin. The crystals were removed by filtration, dissolved as approximately 20 per cent of hemoglobin solution in cold water, and dialyzed for 24 hours against isotonic phosphate buffer, $\mathrm{pH}$ 7.4. Immediately before use this freshly dialyzed hemoglobin was spun at 105,000 $\mathrm{G}$ for 1 hour at $0^{\circ} \mathrm{C}$ in a Spinco Model L ultracentrifuge. In some experiments hemoglobin prepared as described above was further purified by column chromatographic separation. $^{2}$ For this purpose a column of IRC-50 resin, ${ }^{3}$

2 Although the procedure of Drabkin is useful for securing isolated crystals of hemoglobin, it is difficult in bulk procedures to exclude small amounts of other proteins which may also precipitate under the conditions employed.

3 Rohm and Haas Co., Washington Square, Philadelphia, $\mathrm{Pa}$. 
equilibrated with a phosphate buffer (developer no. 2) at $7^{\circ} \mathrm{C}$, was employed (30).

Unless otherwise indicated the hemolytic compounds employed were dissolved immediately prior to use in cold isotonic phosphate buffer, $\mathrm{pH} 7.4$, except with phenylhydrazine hydrochloride, to which an equivalent of sodium hydroxide was also added. Phenylhydrazine and acetylphenylhydrazine were selected for use in most of the experiments since they are the most extensively studied of the hemolytic compounds and are active in vitro as well as in vivo.

Unless otherwise stated, hemoglobin or red cell preparations were incubated in siliconized, $50 \mathrm{ml}$ Erlenmeyer flasks in a Dubnoff metabolic shaker. Experiments were terminated by placing the flasks in an ice bath.

Methemoglobin and so-called sulfhemoglobin were measured by the Evelyn-Malloy method (31). Specimens for this purpose were diluted in ice cold $\mathrm{M} / 15$ phosphate buffer, $\mathrm{pH}$ 6.6, and then filtered through no. 12 Whatman paper before optical readings were made.
Spectrophotometric analyses were made with the Beckman model 2400 DU spectrophotometer on $0.01 \mathrm{mM}$ hemoglobin solutions dialyzed at $4^{\circ} \mathrm{C}$ overnight against $\mathrm{M} / 15$ phosphate buffer, $\mathrm{pH}$ 6.6. Optical density readings were made at $5 \mathrm{~m} \mu$ intervals over a range of from 200 to $1,000 \mathrm{~m} \mu$.

Red cell suspensions were examined microscopically for inclusion bodies after supravital staining with isotonic aqueous solutions of crystal violet and of methyl violet. Suspensions of precipitated hemoglobin were examined in the same way.

The weight of precipitates derived from drug-treated hemoglobin solutions and from water-hemolyzed red cell suspensions was determined by centrifuging the preparations in cellulose tubes at $105,000 \mathrm{G}$ for 30 minutes at $0^{\circ} \mathrm{C}$; the supernatant fluid was then decanted and replaced with water and a second, similar centrifugation was performed. Thereafter the supernatant fluid was removed, and the precipitate was desiccated and weighed Elution chromatography of hemoglobin solutions (30)

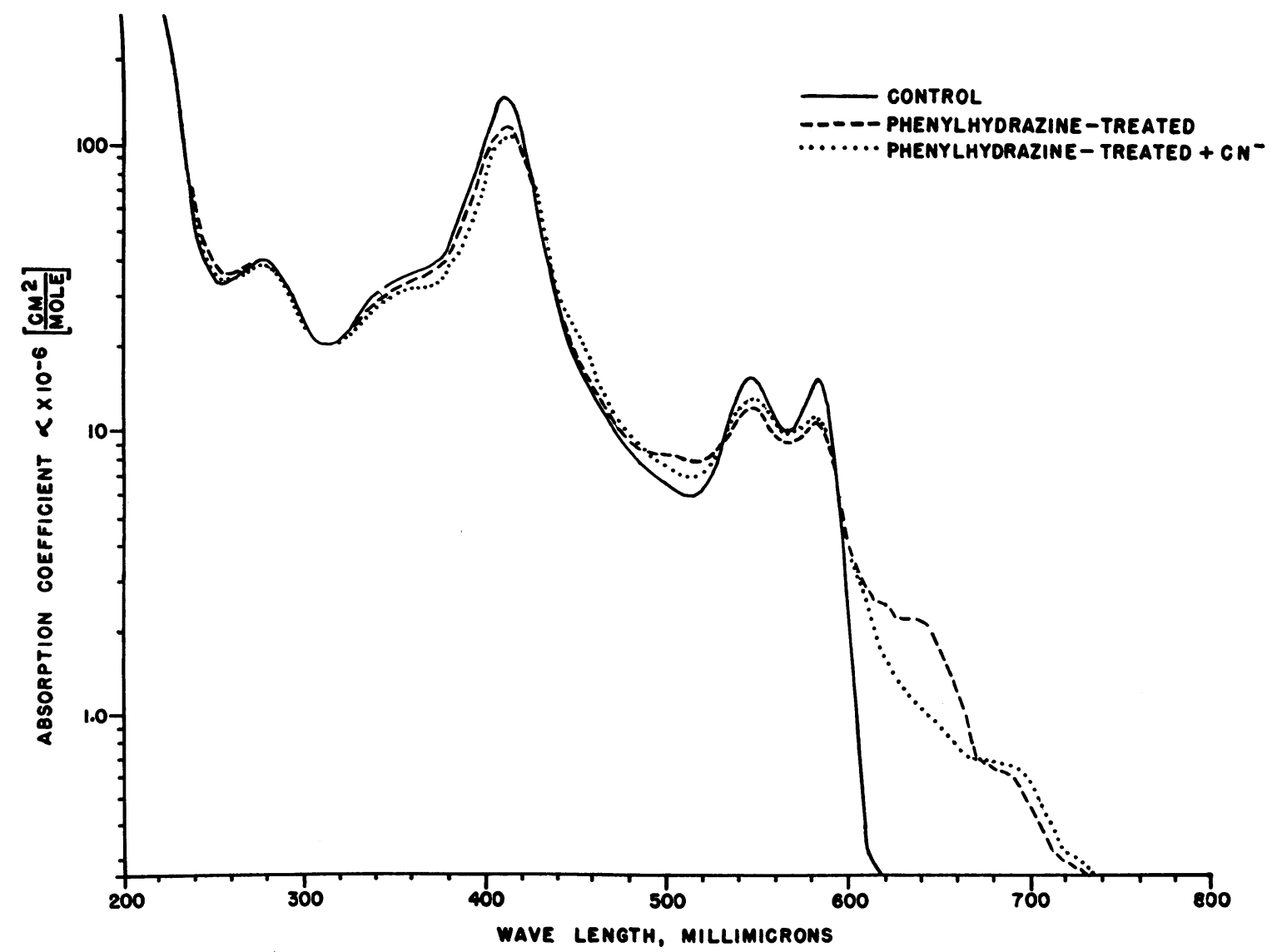

Fig. 1. Changes in light absorption characteristics of hemoglobin on exposure to phenylhydrazine. As compared to the absorption pattern of the "control" hemoglobin (uninterrupted line), hemoglobin exposed to phenylhydrazine (interrupted line) showed a diminution of the Soret peak at 410 to $420 \mathrm{~m} \mu$ and of the twin peaks at 540 and $580 \mathrm{~m} \mu$ characteristic of oxyhemoglobin. The increased absorption at 500 and $635 \mathrm{~m} \mu$, which diminished on the addition of cyanide (dotted line), indicates methemoglobin, while the diffuse absorption above $610 \mathrm{~m} \mu$ even after cyanide indicates "sulfhemoglobin" and related compounds. Note the use of a logarithmic scale on the ordinate. 
was carried out with the IRC resin column described above. Filter paper electrophoresis was performed with the glass plate apparatus (32) and with $0.05 \mathrm{M}$ barbital buffer, $\mathrm{pH}$ 8.6. Hemoglobin specimens were treated with one heme-equivalent of sodium cyanide prior to application.

Three-times crystallized heme was provided by Dr. Rudi Schmid. Methemalbumin was prepared as described by Rosenfeld and Surgenor (33). Globin was produced from crystalline hemoglobin by the method of Rossi-Fanelli, Antonini and Caputo (34).

\section{RESULTS}

The effects of phenylhydrazine and acetylphenylhydrazine on hemoglobin

1. Spectrophotometric changes. The color changes produced in hemoglobin (either in solu- tion or within red cells) by phenylhydrazine and related compounds varied with the dose and duration of the exposure (as shown below). The spectroscopic changes in hemoglobin solution exposed to 4 equivalents ${ }^{4}$ of phenylhydrazine are shown in Figure 1. Phenylhydrazine caused a diminution of the double peaks of absorption, at 540 and $580 \mathrm{~m} \mu$, which are characteristic of oxyhemoglobin, and in larger doses (not shown here) caused their replacement with a single peak at 540 $\mathrm{m} \mu$. The increased absorption at $500 \mathrm{~m} \mu$ and the presence of a peak at 635, which disappears after

4 The calculations of mole equivalent are based on a molecular weight of 68,000 for hemoglobin, of 145 for phenylhydrazine hydrochloride, and of 146 for acetylphenylhydrazine.

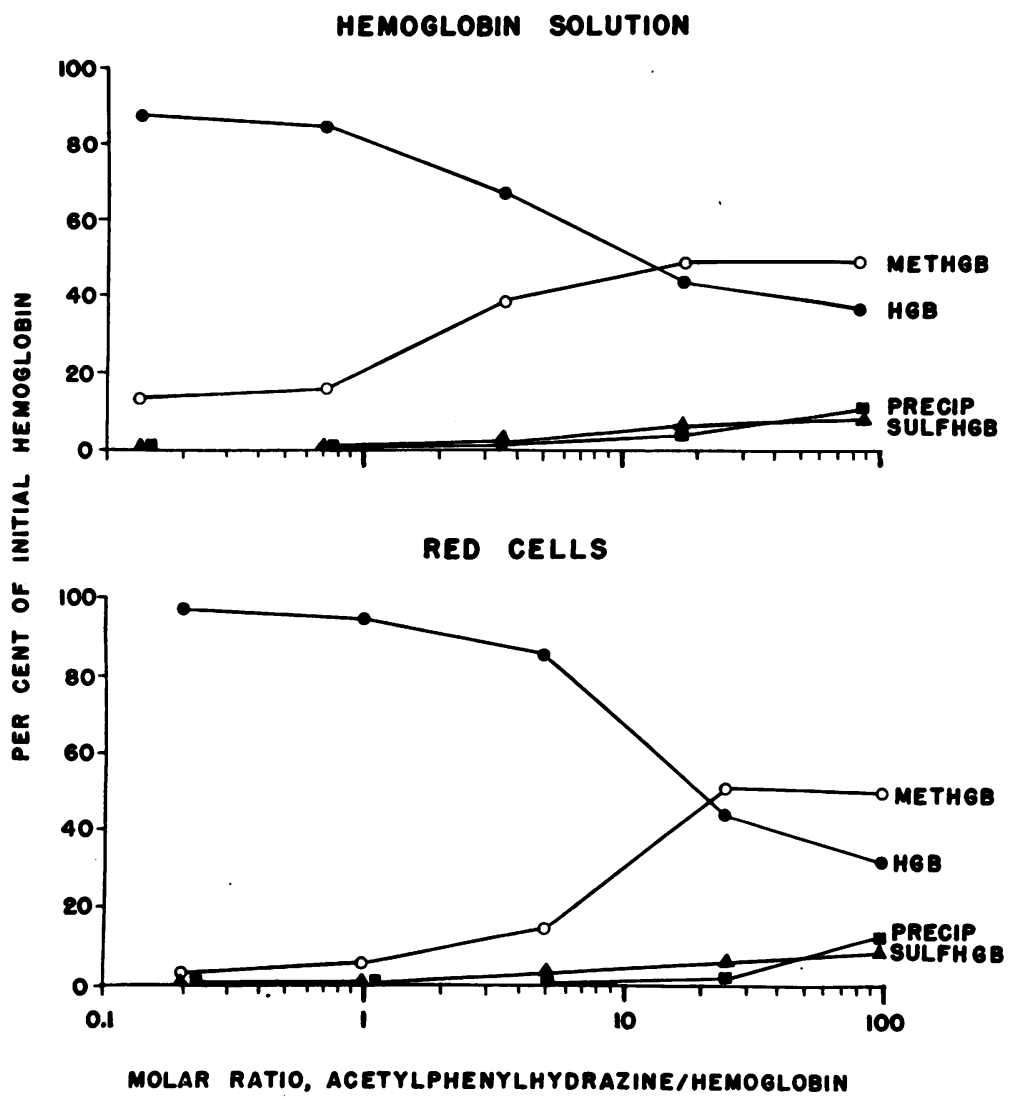

Fig. 2. EFFECTS OF VARIOUS QUANTITIES OF ACETYLPHENYLHYDRAZINE ON HEMOGLOBIN IN SOLUTION (ABOVE) AND WITHIN WASHED RED CELLS (BELOW). Apart from the fact that the solutions of crystalline hemoglobin contained 12 per cent methemoglobin to begin with, the levels of methemoglobin (empty circles), sulfhemoglobin (black triangles), and of hemoglobin (ferrohemoglobin) (black circles) were similar in the two preparations. In the red cell preparation the water-soluble precipitate value (black squares) was corrected for the weight of the stroma of untreated cells. 


\section{OXYHEMOGLOBIN SOLUTION}

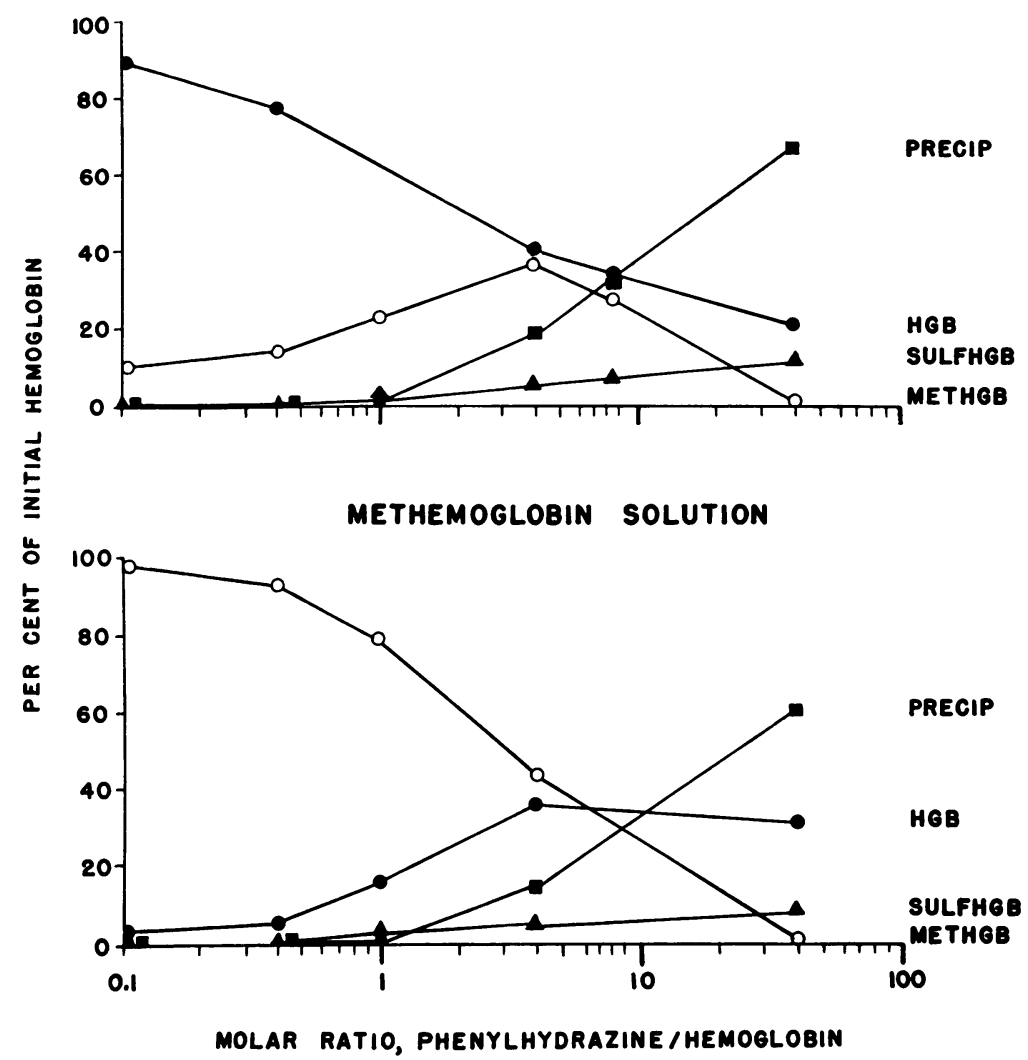

Fig. 3. EFFECTS OF VARIOUS QUANTITIES OF PHENYLHYDRAZINE ON SOLUTIONS OF OXYHEMOGLOBIN (ABOVE) AND OF METHEMOGLObin (BELOW). MaXimum methemoglobin levels were attained with 4 volumes of phenylhydrazine per mole of oxyhemoglobin (i.e., the drug was equimolar with heme), at which dose the same oxyhemoglobin/methemoglobin equilibrium was attained whether the starting material was oxyhemoglobin or methemoglobin. At higher doses of drug methemoglobin was either reduced or precipitated.

cyanide, are characteristic of methemoglobin. The diffuse increase in absorbance above $610 \mathrm{~m} \mu$, declining gradually with increasing wave lengths and not removed by cyanide, is a feature of those irreversibly denatured hemoglobins, or hemochromagens, referred to earlier. Since in the EvelynMalloy procedure, employed in the kinetic studies below, the persistent absorption of hemoglobin derivatives at $620 \mathrm{~m} \mu$ after cyanide is used to measure "sulfhemoglobin," and since there is no general agreement on the nomenclature of substances with this characteristic, the term sulfhemoglobin will be employed arbitrarily hereafter to indicate such substances.

2. The effect of dose. The effects of various amounts of acetylphenylhydrazine on hemoglobin solutions and on washed red cell suspensions dur- ing 2 hours' incubation at $37^{\circ} \mathrm{C}$ are depicted in Figure 2. In both preparations methemoglobin appeared within this period of time when equimolar amounts of the drug were used, while sulfhemoglobin and a precipitate appeared in appreciable quantities only at higher drug levels. The amount of methemoglobin produced reached a maximum in both preparations at a drug concentration of about 20 equivalents. No further increase was produced at drug levels of about 100 equivalents, although the amount of sulfhemoglobin and the weight of precipitate were increased.

A comparable study of the effects of various amounts of phenylhydrazine on solutions of crystalline hemoglobin is presented in the upper portion of Figure 3. With this agent methemoglobin was produced in appreciable amounts by as little 
as 0.4 equivalent and reached a maximum at 4 equivalents of phenylhydrazine. At still higher levels of the drug the methemoglobin was reduced again to hemoglobin (see below). The maximum methemoglobin level corresponds to the point at which phenylhydrazine and heme are at equivalence. As with acetylphenylhydrazine, higher concentrations of drug were required to produce sulfhemoglobin and to precipitate the hemoglobin than those needed to produce methemoglobin; in- deed, precipitation and sulfhemoglobin formation were greatest at levels of drug which had completely reduced the methemoglobin. Note that in a 2 hour period of incubation phenylhydrazine is considerably more potent than acetylphenylhydrazine in degrading hemoglobin.

3. Time relationship. The relative amounts of methemoglobin, sulfhemoglobin, and precipitated hemoglobin at various time intervals after the addition of 20 equivalents of phenylhydrazine or of

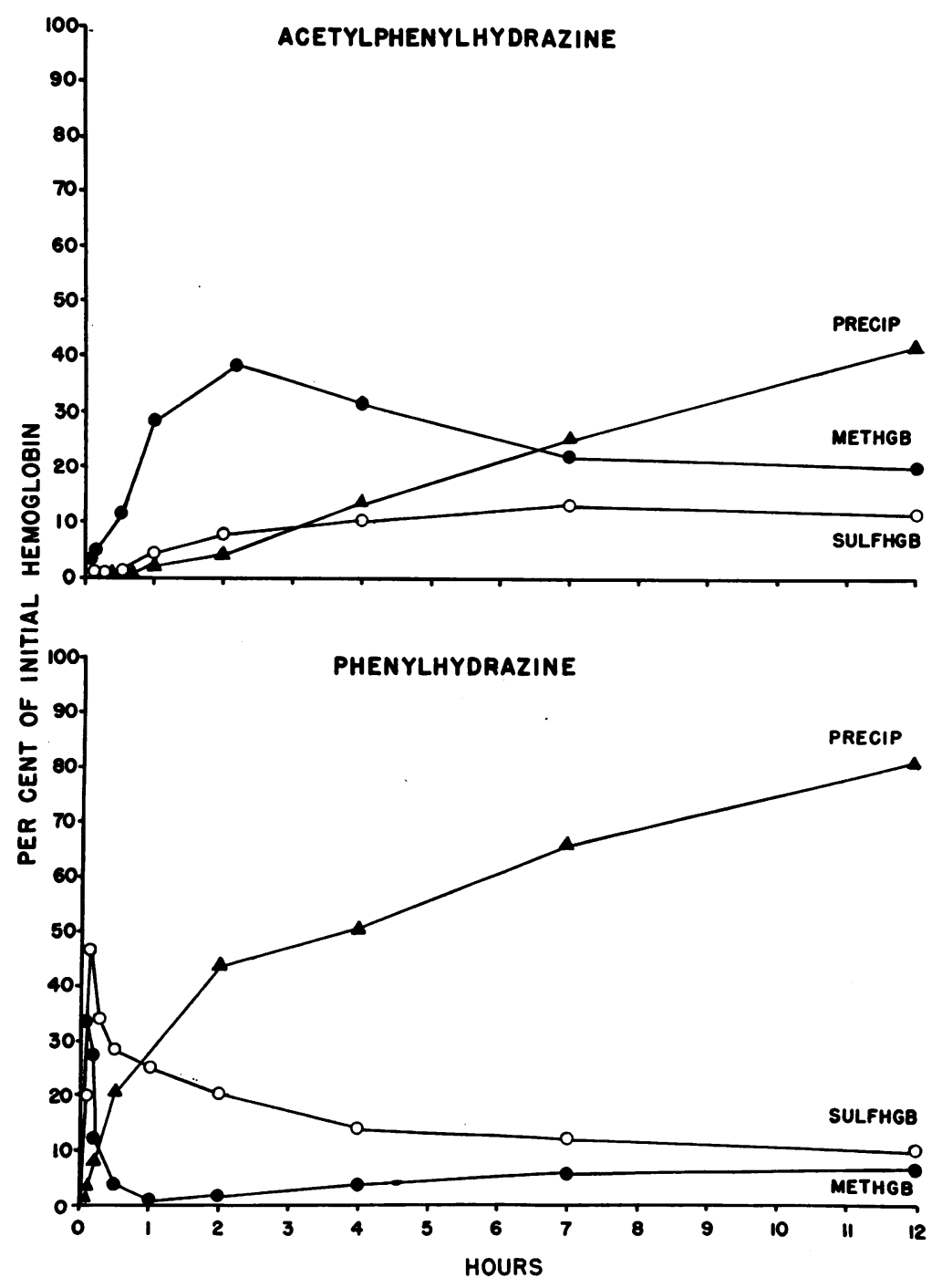

Fig. 4. SEQUENTIAL CHANGES IN HEMOGLOBIN EXPOSED TO ACETYLPHENYLHYDRAZINE (ABOve) AND to PHENYLhydRAZINE (BELOW). Unlike phenylhydrazine, which causes immediate injury to solutions of hemoglobin, acetylphenylhydrazine becomes "active" only after a delay period. Note the early, transient appearance of methemoglobin followed by the later, transient appearance of sulfhemoglobin, and finally the conversion of pigment into a precipitate. 
acetylphenylhydrazine per equivalent of hemoglobin are presented in Figure 4. It is apparent that phenylhydrazine acts rapidly in terms of pigment changes with an accompanying, but continuing, precepitation of hemoglobin. The concentrations of methemoglobin and sulfhemoglobin at this dose of phenylhydrazine were maximal within 1 minute of admixture; thereafter methemoglobin levels fell off rapidly and sulfhemoglobin levels declined gradually in reciprocal relation to the accumulating amount of precipitate. Acetylphenylhydrazine in the same concentration produced a gradual rise in methemoglobin levels, which reached a maximum in 2 hours and then declined, disappearaing completely within 20 hours (not shown). Sulfhemoglobin first appeared after 30 minutes' incubation, reached a maximum several hours later, and then declined gradually. Precipitated hemoglobin accumulated slightly more slowly at first, but steadily increased thereafter; by 20 hours (not shown) the total amount of hemoglobin precipitated reached 75 per cent of the hemoglobin initially present in solution, almost as much as was precipitated by phenylhydrazine.

4. The precipitate. That the precipitated material in the experiments cited above was precipitated hemoglobin, and not precipitated drug, is evident from purely gravimetric considerations. The precipitate was dark brown and granular in gross appearance. The granules tended to form uniform, small clumps and hair-like strands on standing. Although insoluble in water or $0.1 \mathrm{~N}$ $\mathrm{NaCl}$ the precipitate could be dissolved slowly in $0.1 \mathrm{~N} \mathrm{NaOH}$ or $0.1 \mathrm{~N} \mathrm{HCl}$ and readily dissolved in $8 \mathrm{M}$ urea. It was solubilized within 2 to 3 hours by digestion at $37^{\circ} \mathrm{C}$ in 0.03 per cent crystalline trypsin in phosphate buffer, $\mathrm{pH} 7.8$. Solutions of precipitate in $0.1 \mathrm{~N} \mathrm{NaOH}$ showed a Soret-type absorption band at $405 \mathrm{~m} \mu$. This band was similar in position but only 54 per cent as intense as that of an equivalent amount by weight of oxyhemoglobin examined in the same solvent. A pyridine extract of the washed precipitate showed an intense absorption band at 558 $\mathrm{m} \mu$ when reduced with sodium metabisulfite (forming a reduced pyridine hemochromagen) indicating the presence of heme.

Simultaneous studies of the effects of phenylhydrazine or acetylphenylhydrazine on red cells as compared to hemoglobin solutions revealed that Heinz bodies formed in the cells coincident with the appearance of a visible precipitate in the solution. Microscopic examination revealed a striking similarity in the appearance of the granules in red cells and the granules precipitated in hemoglobin solutions, as regards size, shape, aggregating characteristics, and staining qualities. In Figure 5 granules of hemoglobin precipitated by phenylhydrazine are compared with Heinz bodies produced in red cells at the same time by phenylhydrazine.
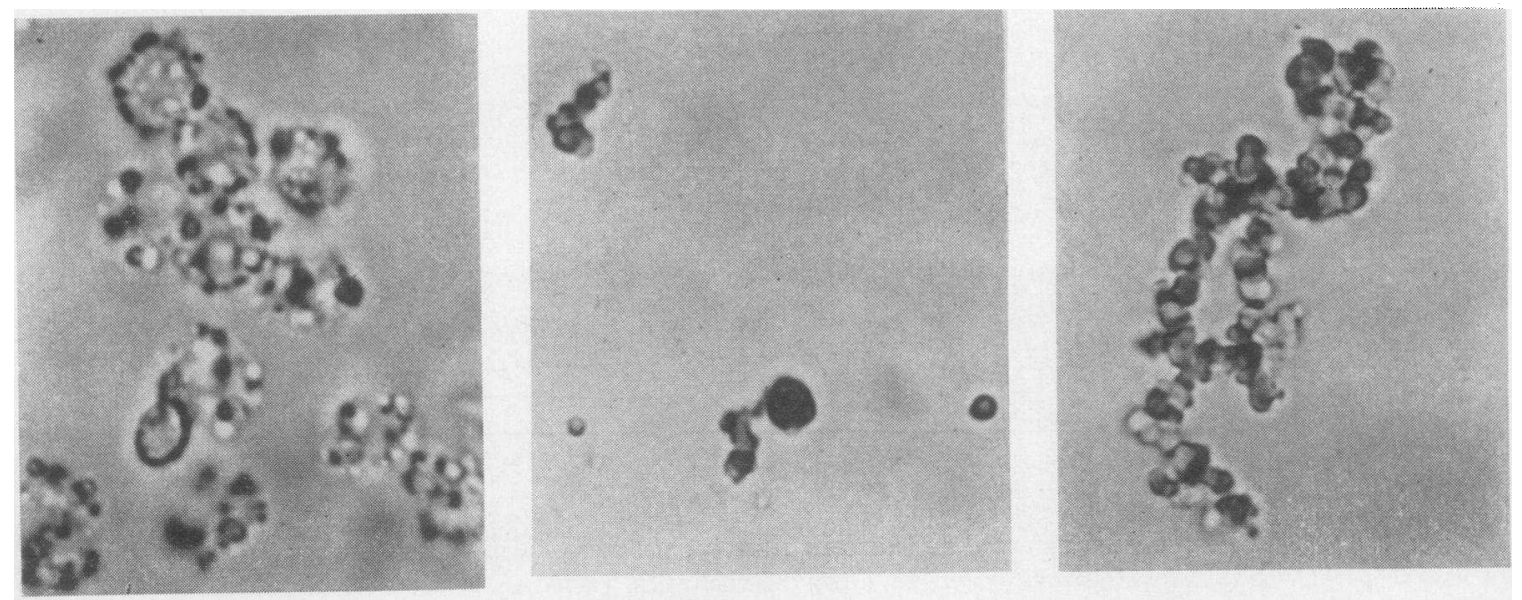

Fig. 5. Comparison of precipitated hemoglobin and of Heinz bodies produced by phenylhydrazine. The photographs were taken of crystal violet-stained suspensions of red cells containing Heinz bodies (left) and of precipitated hemoglobin (middle and right) 2 hours after the addition of phenylhydrazine. The aggregate of unstained, precipitated hemoglobin granules at the right shows the characteristic tendency of these spheroidal bodies to align in irregular, branching chains. (Magnification $\times 2,000$.) 
The granules of precipitate varied in size from barely visible specks early in their formation to spherules 2 to $3 \mu$ in diameter later on. These spherical particles tended to align themselves at first in short chains, then in irregular, branching chains, and finally in large aggregates. Some particularly long chains had the gross appearance of hair. The granules were identical in appearance to those Heinz bodies which had been extruded into the suspending medium from red cells. The conclusion seems warranted that Heinz bodies are themselves simply particles of precipitated, denatured hemoglobin and that their apparent structure simply reflects the physical configuration peculiar to precipitates of this protein.

The question as to whether this type of hemoglobin precipitate is peculiar to the effect of phenylhydrazine-like drugs was examined by precipitating hemoglobin with acid or with heat. Precipitation by exposure to $0.2 \mathrm{~N} \mathrm{HCl}$ for periods of time, ranging between 30 seconds and 1 hour, before neutralization with $0.2 \mathrm{~N} \mathrm{NaOH}$, caused a precipitate of fine granules that resembled those appearing shortly after the addition of phenylhydrazine but that never achieved the size which the latter eventually attained. Precipitation of hemoglobin at $75^{\circ} \mathrm{C}$ caused granules to appear within 30 seconds that closely resembled those formed by phenylhydrazine, differing only in that there was little discoloration. Although heating at $75^{\circ} \mathrm{C}$ for 5 minutes produced a heavy, granular precipitate which stained blue with crystal violet, relatively little methemoglobin was produced and there was no sulfhemoglobin.

Human serum albumin and ovalbumin were not visibly affected by phenylhydrazine or acetylphenylhydrazine. Methemalbumin showed no tendency to precipitate in the presence of these drugs. Purified native globin spontaneously precipitated during incubation at $37^{\circ} \mathrm{C}$ under oxygen. The rate of this precipitation was not apparently influenced by phenylhydrazine. Except for its light color, the precipitate of globin was identical in appearance to that of drug-treated hemoglobin.

5. Electrophoretic and chromatographic changes. Both phenylhydrazine and acetylphenylhydrazine produced changes in the mobility of hemoglobin by paper electrophoresis at $\mathrm{pH} 8.6$ (Figure 6). Both with red cells and with hemoglobin solutions, these drugs caused the appearance of a color peak
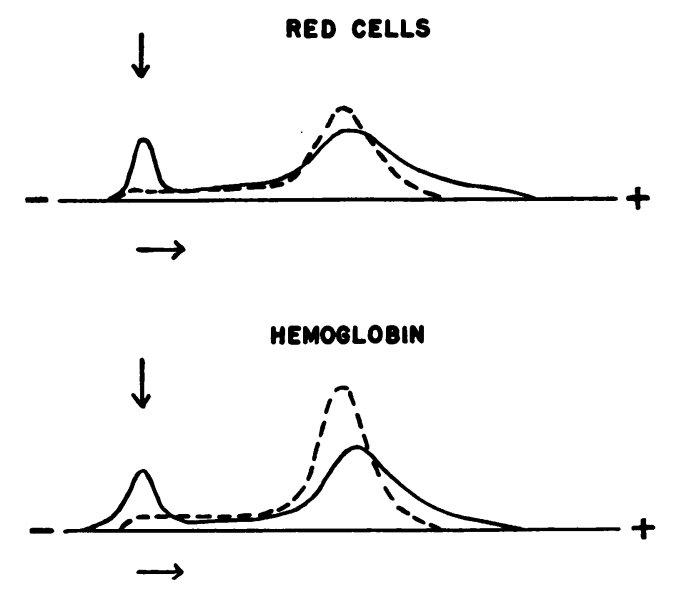

Fig. 6. Changes in hemoglobin Mobility on 'EleCTROPHORESIS AT PH 8.6 BEFORE (INTERRUPTED LINES) AND AFTER (CONTINUOUS LINES) THE ADDITION OF PHENYLHYDRAZINE. With hemoglobin either in red cells (above) or in solution (below), phenylhydrazine produced a greenish-brown peak which remained at the origin (beneath the vertical arrows) and a fast-moving component. The main peak was either unchanged in position or only slightly faster than normal.

which remained at the origin. This immobile peak was present even in clear, ultracentrifuged specimens, and was greenish-brown in color. The majority of the drug-treated hemoglobin was brownish-red (after cyanide) and showed approximately the mobility of normal hemoglobin; however, the color peak on electrophoretic strips tended to be slightly faster than normal (most evident in the lower portion of Figure 6) and a conspicuous fast-moving minor component was present. These changes appeared at concentrations of drug that produced methemoglobin with little or no sulfhemoglobin and no precipitate, and became more striking with bigger doses. Only with virtually complete precipitation of hemoglobin by phenylhydrazine did the mobile hemoglobin peak of the remaining soluble hemoglobin convert entirely into a fast-moving component; under these extreme conditions this peak was greenish-brown and broadly smeared.

After exposure to either phenylhydrazine or acetylphenylhydrazine there were changes in the behavior of hemoglobin on ion-exchange (IRC-50) resin columns. Normal hemoglobin on such a column can be separated into several fractions (30), including $A_{I}$, a front-running component which under standard conditions comprises about 
10 per cent of the total and may include the fetal hemoglobins, and $\mathrm{A}_{\mathrm{II}}$, a slower-moving component comprising almost 90 per cent of the total. Although these fractions are not completely analogous to those found on electrophoresis, a portion of the front-running chromatographic fraction has an electrophoretic mobility corresponding to the "fast" hemoglobin of Kunkel and Wallenius (35). Hemoglobin treated with either of these two drugs showed an increase in the percentage of the frontrunning $\left(A_{I}\right)$ fraction with a corresponding decrease in the main $\left(A_{I I}\right)$ component. This increased $A_{I}$ fraction did not differ in its spectroscopic properties from the $A_{I I}$. $A_{I}$ and $A_{I I}$ fractions previously prepared by chromatographic separations were equally susceptible to degradation by phenylhydrazine. On exposure to phenylhydrazine Fraction $A_{I I}$ was almost entirely converted into $\mathrm{A}_{\mathrm{I}}$.

\section{Factors influencing the action of phenylhydrazine- like drugs on hemoglobin}

1. Temperature. At $0^{\circ} \mathrm{C}$ acetylphenylhydrazine produced no measurable change in the hemoglobin of either red cells or of hemoglobin solutions in the 2 hour period of observation.

2. Gas phase. Under nitrogen, using hemoglobin solutions largely depleted of oxygen by repeated flushing with nitrogen in a tonometer, phenylhydrazine and acetylphenylhydrazine caused partial reduction of the initial concentration of methemoglobin, some sulfhemoglobin appeared, but there was no precipitation. Under these conditions red cells did not develop Heinz bodies.

Under an atmosphere of pure carbon monoxide, phenylhydrazine reduced all of the original methemoglobin of hemoglobin solutions, traces of sulfhemoglobin appeared, but there was no precipitation and in red cells there were no Heinz bodies. In an atmosphere of 10 per cent carbon monoxide and 90 per cent oxygen, about 70 per cent as much precipitate formed as under 100 per cent oxygen.

3. Heme complexes. The experiment immediately above indicated that carbon monoxyhemoglobin was less susceptible than oxyhemoglobin to denaturative precipitation by phenylhydrazine even when oxygen was present in the gas phase. However, it is clifficult to dissociate effects on hemoglobin due to the displacement of oxygen from those due to the stabilizing effect of carbon monoxide.
In the presence of a large excess of sodium cyanide (up to 100 equivalents relative to hemoglobin) the precipitative effect of acetylphenylhydrazine or of phenylhydrazine on hemoglobin in solution or in cells was only slightly diminished, and there was some increase in sulfhemoglobin as compared to the results when cyanide was omitted.

Solutions of oxyhemoglobin were compared with methemoglobin prepared by pretreating some of the hemoglobin solution with 1.2 heme-equivalents of potassium ferricyanide at $\mathrm{pH} 6.8$, followed by dialysis. As shown in the upper part of Figure 3 , almost 40 per cent of the hemoglobin of oxyhemoglobin solutions was oxidized to methemoglobin by 4 equivalents ( 1 heme-equivalent) of phenylhydrazine; at higher levels of this drug the methemoglobin concentration diminished along with the level of total soluble hemoglobin. When all of the initial hemoglobin was in the form of methemoglobin, as inclicated in the lower part of Figure 3, the level of methemoglobin fell, rather than rose, on exposure to phenylhydrazine, so that once again at a dose of 4 equivalents of phenylhydrazine, approximately 40 per cent of the hemoglobin was methemoglobin. Higher concentrations of phenylhydrazine caused further reduction of the methemoglobin and total hemoglobin levels. Note that regardless of the oxidation state of the heme iron to begin with, 1 hemeequivalent of phenylhydrazine produced approximately a 50:50 equilibrium between ferroheme and ferriheme (hemoglobin and methemoglobin). There was no difference between these solutions in the total quantity of sulfhemoglobin or precipitate produced. When methemoglobin prepared with ferricyanide as described above was treated with 1.2 heme-equivalents of sodium cyanide prior to the addition of phenylhydrazine, none of the resultant methemoglobin cyanide was reduced by phenylhydrazine and no precipitate or sulfhemoglobin was formed, even under an atmosphere of 95 per cent oxygen.

4. Effects of preincubation of acetylphenylhydrazine. Although preincubation of acetylphenylhydrazine with oxygen and traces of metal ions caused a marked increase in its ability to oxidize glutathione (36), no such potentiation of its ability to precipitate hemoglobin could be demonstrated. Initially, slightly more methemoglobin was formed from hemoglobin treated with oxygen-preincubated 
acetylphenylhydrazine than by the nitrogen-preincubated drug. When a 0.5 per cent solution of hemoglobin reacted with a $250 \mathrm{M}$ excess of acetylphenylhydrazine preincubated under oxygen for 2 hours, 2 per cent methemoglobin formed in 30 seconds, whereas, when the acetylphenylhydrazine was preincubated under nitrogen, no methemoglobin formed within the first 50 seconds.

5. Comparative effect of several redox compounds. As noted above, phenylhydrazine caused a considerably more rapid destruction of hemoglobin than did acetylphenylhydrazine. Hydroxylamine, like phenylhydrazine, produced a rapid conversion of hemoglobin successively to methemoglobin and then to sulfhemoglobin and precipitated hemoglobin; $p$-aminophenol closely resembled phenylhydrazine in its effects on hemoglobin; $o$-aminophenol acted similarly in terms of methemoglobin formation but caused less sulfhemoglobin and precipitate. Aside from a slight in-
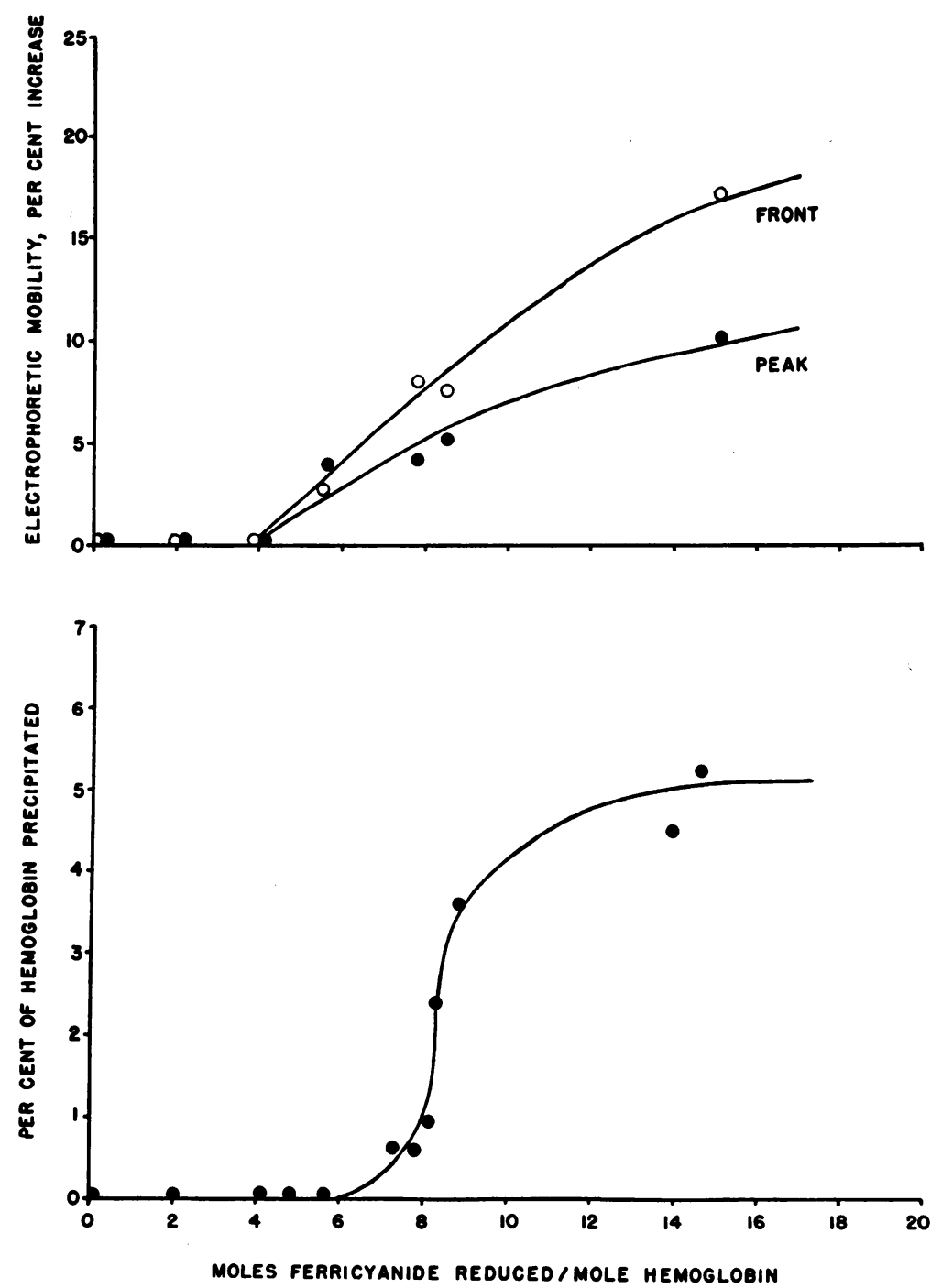

Fig. 7. Changes in hemoglobin mobility on electrophoresis at PH 8.6 AND PRECIPITATION OF HEMOGLOBIN THROUGH ITS OXIDATION BY POTASSIUM FERRICYANIDE. As shown in the upper portion, there was an increase in the mobility of the fast-moving component ("front") and of the main component ("peak") of hemoglobin when more than four oxidation steps had occurred. Precipitation occurred (lower portion) when more than 6 equivalents of ferricyanide had been reduced by hemoglobin to ferrocyanide. 


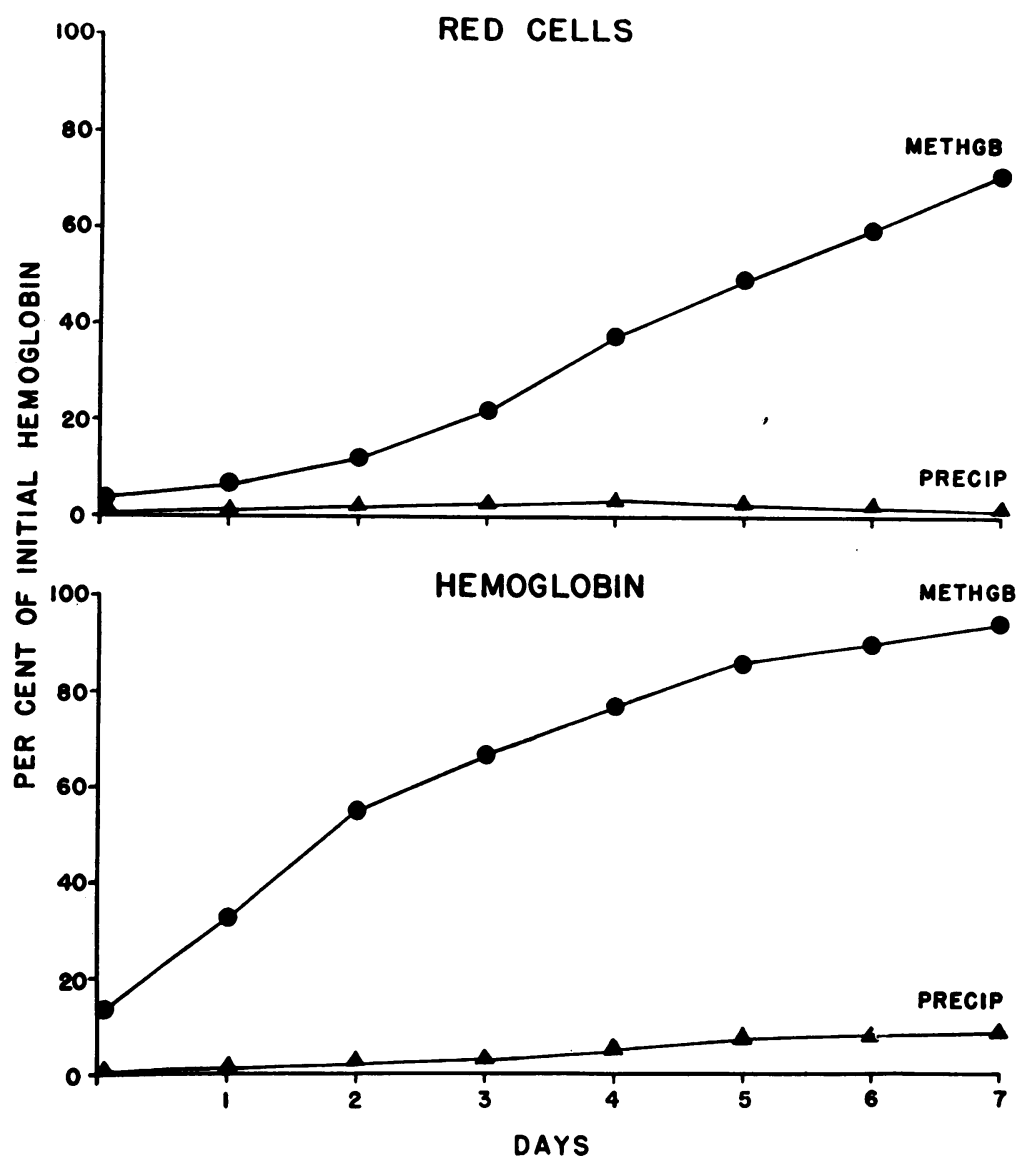

Fig. 8. EFFect of prolonged sterile incubation at $37^{\circ} \mathrm{C}$ on Red Cell SUSPENSIONS AND ON SOLUTIONS OF HEMOGLOBIN. In red cells (above) hemoglobin was converted to methemoglobin slowly during the first 2 days and then more rapidly and steadily thereafter. In solutions of hemoglobin (below ) methemoglobin appeared at a rate of almost 1 per cent per hour for the first 2 days and then accumulated more slowly thereafter.

crease in methemoglobin, hemoglobin was unaffected by $m$-aminophenol.

6. Effect of "simple" oxidants. Potassium ferrocyanide, unlike some of the compounds above, is slow to auto-oxidize. Therefore, potassium ferricyanide is often employed stoichiometrically as a "simple" oxidant relative to heme. As expected, 4 moles of ferricyanide per mole of hemoglobin ( 1 heme-equivalent) converted all of the oxyhemoglobin to methemoglobin. At $\mathrm{pH} 6.8$, where hemoglobin sulfhydryl groups are comparatively unreactive (37), 10 equivalents of ferricyanide added to hemoglobin produced no precipitate or sulfhemoglobin. At $\mathrm{pH} 9.1$ in borate buffer 10 equivalents of ferricyanide produced in 3 hours at $37^{\circ} \mathrm{C}$ a precipitate equal to that caused by 4 equivalents of phenylhydrazine under the same conditions. While producing more methemoglobin, ferricyanide caused less sulfhemoglobin to appear than did phenylhydrazine. As did phenylhydrazine, ferricyanide caused an increase in the fast-moving component of hemoglobin on electrophoresis and on column chromatography.

In order to determine the number of oxidation steps necessary for the described changes in hemoglobin to occur, studies were conducted in which various amounts of ferricyanide were added to solutions of hemoglobin at $\mathrm{pH} 9.1$, and the amount of methemoglobin and hemoglobin precipitate formed and the changes in the electrophoretic behavior of hemoglobin were compared with the number of equivalents of ferrocyanide elaborated. Ferrocyanide was measured by means of the Prussian blue reaction (37). As indicated 
in Figure 7, no change occurred in the electrophoretic mobility of hemoglobin when less than 4 equivalents of ferrocyanide had formed; the first 4 equivalents of ferricyanide added had quantitatively oxidized the hemoglobin to methemoglobin as expected (37). With the reduction of slightly more than 4 equivalents of ferricyanide to ferrocyanide by hemoglobin, an increase in electrophoretic mobility became evident. When hemoglobin reduced more than 6 equivalents of ferricyanide, a gradual precipitation of hemoglobin ensued. Precipitation was inhibited by carbon monoxide. Under oxygen, precipitation of hemoglobin by ferricyanide was slower than by phenylhydrazine. These studies indicate that with the removal of two or more electrons from globin, changes occur in the hemoglobin molecule which permit its denaturative precipitation by oxygen.

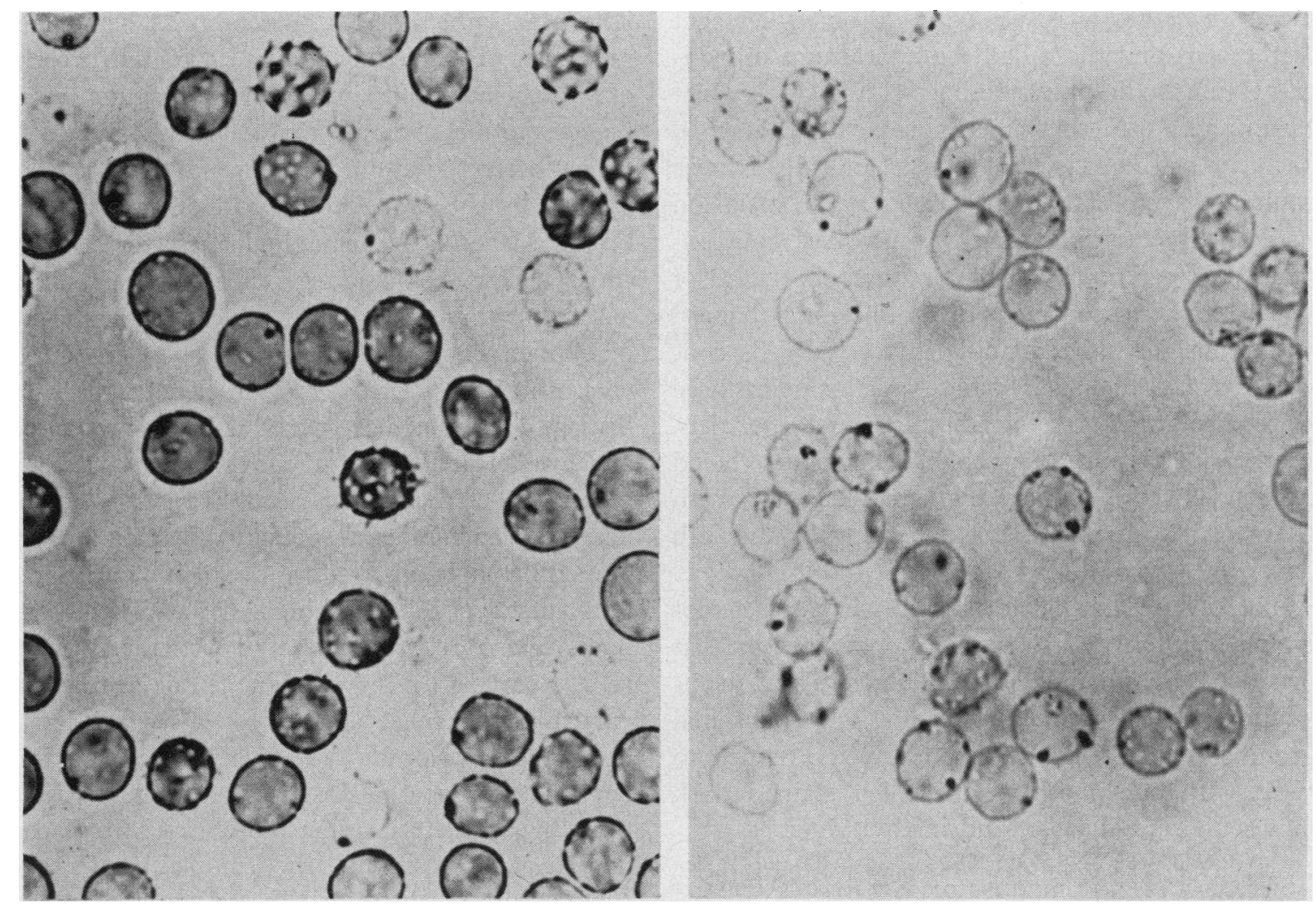

Fig. 9. Appearance of Heinz bodies in normal Red cells after sterile incubation at $37^{\circ} \mathrm{C}$ FoR 4 days (LEFT) AND FOR 7 DAYS (RIGHT). At 4 days most of the cells are slightly irregular and crenated, showing refractile spicules and containing, in about one-quarter of the cells, one to three dark-staining inclusions resembling Heinz bodies. Virtually all ghosts, as shown in this picture, contained several such inclusions. After 7 days most of the cells (and all of those in the picture to the right) were ghosts, most of which contained several darkstaining inclusions resembling Heinz bodies. (Magnification $\times 2,000$.) 
secliment of the water hemolysate spun at 105 ,$000 \mathrm{G}$ for 1 hour, was corrected for the weight of the sedimented cell membranes on "Day 0". This precipitate tended to increase slowly during the first several days, and then to decline somewhat as cell membranes became more difficult to recover by centrifugation. Prolonged incubation of hemoglobin alone (lower portion of Figure 8) caused methemoglobin to form at the rate of about 18 per cent per day for the first 2 to 3 days, with a gradual decline in increment thereafter. Here again sulfhemoglobin (not shown) appeared after the third day in only trace amounts, never exceeding 3 per cent of the total. A slight precipitate was visible within 48 hours and this increased in amount steadily in the ensuing 6 days.

Microscopically, the red cells underwent increasing crenation during the first 2 days and thereafter ghosts became evident in small numbers. By the third or fourth day, from 1 to 3 inclusion bodies were visible in 20 or 30 per cent of the cells and these had the appearance of typical Heinz bodies on staining with crystal violet (Figure 9). At this time approximately 5 or 10 per cent of the cells were ghosts and all of these contained from 2 to $10 \mathrm{Heinz}$ body-like inclusion bodies. By the sixth and seventh days approximately 70 per cent of the cells were ghosts, all of which contained from 2 to 15 inclusion bodies, while most of the remaining intact red cells contained from 1 to 4 such bodies. At this point there were also many free granules around the cells. Sterile incubation of whole defibrinated blood produced very similar pigment changes, with characteristic Heinz bodies appearing by the fifth day.

The precipitate that formed in incubated hemoglobin solutions had the same appearance as that produced by phenylhydrazine and related compounds; there were aggregates of spheroidal granules up to $1 \mu$ in diameter, which tended to align with one another and which stained dark blue with crystal violet and methyl violet.

\section{DISCUSSION}

These studies indicate that phenylhydrazine and related redox compounds which can permeate the red cell membrane cause the same sequence of denaturative changes in hemoglobin, whether the hemoglobin is in pure solution or within red cells.
This sequence involves 1) spectrophotometric changes, 2) electrophoretic and chromatographic changes, and 3 ) precipitation of hemoglobin into coccoid bodies.

Spectroscopic changes. The earliest detectable change in hemoglobin on exposure to phenylhydrazine-like compounds in itro is the appearance of a compound with the spectroscopic characteristics of methemoglobin. Since all of a large group of drugs tested by Emerson, Castle and Ham (17, 38) for hemolytic activity in vitro produced methemoglobin, it is probable that true methemoglobinemia occurs invariably in the early course of Heinz body anemias. Failure to observe methemoglobin in all instances (4) is probably attributable to its transience, due to the following: 1 ) it is enzymatically reduced within the living cell $(39)$; 2) it reaches a redox equilibrium with compounds such as phenylhydrazine; 3 ) it (in equilibrium with hemoglobin) bears a precursor relationship with a series of denatured hemoglobin products. Presumably, doubt as to the presence of methemoglobin in phenylhydrazine-treated blood, on the grounds that such blood remains brown after the addition of cyanide (40), is explained by the fact that such blood also contains brown denatured hemoglobin products which cause spectroscopic interference by their diffuse absorption in the red, and which gradually supplant methemoglobin at a rate dependent on the concentration of drug. These denatured brown hemoglobins, which are pyridine hemochromagens, and are termed here for convenience "sulfhemoglobin," are in turn replaced by poorly soluble, brown-green pigments, presumably including the "green hemoglobins," some of which may not contain intact porphyrin rings (3). These compounds also absorb diffusely, particularly in the red. Because this may in part be due to turbidity, particular care must be taken to clarify solutions of hemoglobin prior to spectrophotometry. It is beyond the scope of this work to attempt definitions or characterizations of the individual compounds. As a group, the soluble brown-green compounds which absorb in the red showed the following behavior: 1) they followed methemoglobin in order of appearance; 2 ) the color change was not reversed by cyanide, thiollic reduction, or dialysis ; 3 ) their appearance coincided with the appearance of insoluble hemoglobin products and with 
soluble brown-green pigments which were immobile on electrophoresis at $\mathrm{pH} 8.6$ and on ion exchange columns at $\mathrm{pH}$ 7.2. Many of our observations concerning the nature of these hemoglobin derivatives merely affirm previous studies by others, including Warburg, Kubowitz and Christian (40), Kiese (7), Heubner (41), and Beaven and White (8). Similarly, Mills (42) found that acetylphenylhydrazine added to rat hemoglobin led to a mixture of breakdown products of hemoglobin rather than to a single pigment such as choleglobin.

Changes in electrophoretic and chromatographic properties. Shortly before the first appearance of sulfhemoglobin-type pigments after treatment of red cells or hemoglobin solutions with phenylhydrazine or related compounds, there appeared on electrophoresis at $\mathrm{pH} 8.6$ an increase in the fastmoving minor component of hemoglobin, which component did not differ in its spectral absorption pattern from the major hemoglobin component. Only with very large amounts of drug was the majority of hemoglobin converted to fast-moving hemoglobin on electrophoresis. Indeed, this occurred only when most of the hemoglobin had been precipitated. As further published work will show, this increase in electrophoretic mobility differs in certain respects from that produced by simple blocking of hemoglobin thiol groups (36), but resembles that produced by sodium chromate (43) and is similar to the fast component found in senescent red cells $(35,44)$.

The front-running fraction of hemoglobin on IRC resin column chromatography, previously suspected to contain oxidized sulfhydryl groups (30), includes the electrophoretically fast component of normal hemoglobin; this fraction is increased by phenylhydrazine and related compounds. Indeed, it was found that a purified preparation of the main component of hemoglobin $\mathrm{A}$ could be entirely converted into chromatographically fast hemoglobin by such compounds. It is of interest that on standing at room temperature pure preparations of the main component tend to convert spontaneously in part to the fast component.

Taken together, the facts above suggest that in - vivo and in vitro hemoglobin tends with time to increase in charge density, that in vitro this process can be sharply accelerated by phenylhydra- zine-like drugs, and that this change occurs just before and during manifestations of frank denaturation. An analogous increase in the electronegativity of albumin has been observed during the course of its denaturation (45).

Shortly after the appearance of electrophoretically-fast hemoglobin and at the first appearance of pigments resembling sulfhemoglobin, there appeared a brown or brownish-green pigment that failed to move on electrophoretic strips or on the ion exchange column. This pigment (or pigments) was a pyridine hemochromagen and probably contributed to the absorption at $620 \mathrm{~m} \mu$. It was usually associated with the appearance of turbidity or of frank precipitation, and is presumed to be a partly soluble form of denatured hemoglobin.

The nature of Heinz bodies. In appearance and manner of evolution the precipitate of hemoglobin produced by phenylhydrazine-like drugs bore an unmistakable resemblance to Heinz bodies. Indeed, it is reasonable to conclude that Heinz bodies are simply granules of precipitated hemoglobin. Their relatively regular, micellar appearance seems to be determined by those general properties of hemoglobin which cause it to aggregate in a certain way when denatured, whether by these drugs, by heat, or by spontaneous aging. The point at which these spherical granules stop "growing," and their tendency to aggregate is fairly uniform, but is influenced by their rate of formation and by the presence of sulfhydryl compounds (36). It is probable that previous reports that Heinz bodies contain lipid or free iron $(1,2)$ reflect the tendency of these granules to adhere to neighboring structures as well as to each other. It is also perfectly possible that in vivo Heinz bodies may at times accumulate a mantle of other insoluble intracellular material. The suggestion by several workers $(3,12)$ that Heinz bodies contain or consist of denatured globin has been in essence verified, albeit in large measure the hemes remain attached, or are reattached. The precipitate had much the same color qualities as the soluble and partly-soluble brown or greenish-brown pigments described above and is presumably similar in nature to the greenish hemoglobin precipitate observed by Warburg and his associates (40) and by Beaven and White (8) when hemoglobin was treated with acetylphenylhydrazine. The latter 
authors (8) conclucled that the precipitate contained a mixture of protoheme and other ironcontaining pigments bound to denatured globin.

The mechanism of drug action. The previous and present findings cited above are consistent with the proposition that phenylhydrazine and related drugs, in the presence of oxygen, cause a progressive, oxidative destruction of hemoglobin. The changes in hemoglobin may be characterized by the following stages: 1) formation of methemoglobin, 2) increase in electronegativity, 3) formation of sulfhemoglobin-like hemochromes, and 4) frank denaturative precipitation as Heinz bodies. These changes can also be brought about with "simple" oxidants, such as ferricyanide. That phenylhydrazine-like drugs cause an oxidative breakdown of hemoglobin has been postulated or accepted previously by a number of investigators $(3,8,11,12,15,41,46)$.

As a class, drugs which induce Heinz body anemias are either actually, or potentially, highly reactive redox compounds. Those which are active in vitro tend (although at various rates) to oxidize spontaneously under oxygen into compounds which immediately oxidize hemoglobin to methemoglobin and GSH to GSSG. In terms of the latter reaction, at least, the rate of formation of these oxidant derivatives is catalyzed by hemoglobin (36); and it has been shown that hemoglobin in turn catalyzes the degradation of phenylhydrazine and other arylhydrazines to benzene and nitrogen (8), probably through a series of intermediate oxidized compounds, including phenylhydroxylamine, nitrosobenzene (47), hydroxylamine, and phenol (8). Since, to precipitate hemoglobin, these drugs require oxygen and the presence of a reactive heme group, since they enter into a dynamic equilibrium with heme, and since they exceed "simple" (i.e., slowly reversible) oxidants such as ferricyanide in their capacity to precipitate hemoglobin, it appears likely that: 1) these compounds are actual, or potential, intermediates between oxygen and hemoglobin, and 2) in the presence of oxygen these compounds and hemoglobin each catalyze the destruction of the other. Such a hypothesis has been advanced by several investigators including Lemberg and Legge (3), Beaven and White (8) and Emerson, Castle and $\operatorname{Ham}(17,38)$. The latter authors (38) pointed out that most hemolytic drugs were resonating aromatic compounds, similar to the reversible oxidation reduction systems studied by Michaelis (48). Substances of this sort could speed the electron transfer from ferrous heme groups and from the sulfhydryl groups of the hemoglobin to molecular oxygen by providing partially oxidized intermediates, including free radicals, stabilized by resonance. Thus, after their conversion to quinone-like substances by molecular oxygen, they are capable of accepting single electrons in two successive steps to form: 1) quinhydrone analogues, and 2) hydroquinone analogues, while two ferrous heme or sulfhydryl groups are being oxidized. Oxygen itself can be partially reduced to form hydrogen peroxide, a compound more active as an oxidant of heme or of sulfhydryl groups than molecular oxygen and capable of accepting single electrons. However, as compared to the oxidant derivatives of phenylhydrazine and related compounds, hydrogen peroxide is very unstable, especially in the presence of substances with catalase activity. Thus, whereas hydrogen peroxide per se can simulate phenylhydrazine in its destruction of hemoglobin, it does so only when in relatively large amounts in the presence of both oxyhemoglobin and cyanide, the latter presumably blocking the catalase activity of methemoglobin. It seems unlikely, despite previous speculations $(41,49)$, that the active derivative of these drugs is hydrogen peroxide itself. A simple schema as to the probable sequence of events is presented:

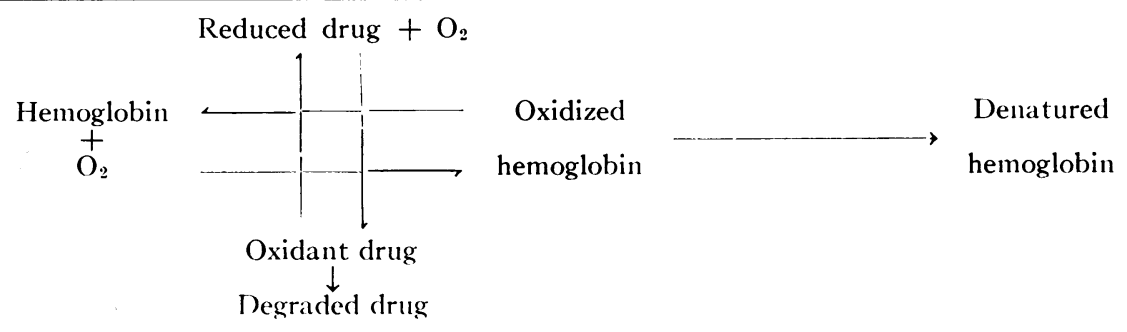


If the effect of these oxidant drugs is then to expedite transmission of the high oxidation potential of molecular oxygen it should be possible to demonstrate that the same changes occur, although more slowly, when hemoglobin is exposed to oxygen alone. Such was indeed the case, for on prolongd incubation under oxygen at $37^{\circ} \mathrm{C}$, but not at $0^{\circ} \mathrm{C}$, solutions of hemoglobin went through, in several days, a sequence similar to that occurring with phenylhydrazine in minutes: conversion to methemoglobin, appearance of "sulfhemoglobin" and a fast-moving component on electrophoresis, and finally precipitation as Heinz body-like granules. Red cells so incubated manifested the same sequence of pigment changes and developed Heinz bodies on the fourth or fifth day. These changes occurred under oxygen but not under carbon monoxide. The spontaneous appearance of inclusion bodies in blood stored for several days has been previously observed by others (50-53). Most of these granules appeared either in reticulocytes $(50,51)$ or represented siderocytes (53), in contrast to the present studies in which the granules occurred in adult red cells and did not stain for iron. Moeschlin (52), on the other hand, observed small, nonsiderotic inclusion bodies in adult red cells which had been incubated for 2 to 3 days at $37^{\circ} \mathrm{C}$, but not at $0^{\circ} \mathrm{C}$, and noted that these inclusions were similar to Heinz bodies in several respects. Because of their marginal placement he termed these bodies "Randkörperchen" and suggested that their presence may presage the death of the red cell.

Whether or not Heinz bodies form during normal red cell aging in vivo, as they do in vitro, is not presently known. Since frank precipitation of hemoglobin may be considered an advanced stage of injury, which may be preceded by more subtle but significant cellular alterations, it seems likely that the spleen, and possibly other elements of the reticuloendothelial system, may remove red cells so injured from the circulation and prevent their accumulation there, provided the number of cells is not too great. It is of interest in this connection that red cells containing Heinz bodies have been reported as a normal finding in splenectomized animals $(54)$ and man $(55,56)$ and in patients with splenic agenesis (57). Therefore, it seems a reasonable possibility that normal aging in vivo is associated with the appearance of Heinz bodies.

Most of the observations reported here have been concerned with the spontaneous or accelerated oxidation of hemoglobin, because that protein is more accessible to observation than are structural components of the cell. The question as to how these observations bear on the fate of the surface and structure of the cell membrane, which determines the survival of the cell in circulation, can at present only be arrived at by analogy. Teleologically it would be desirable to dispense with a red cell containing denatured hemoglobin or hemoglobin with abnormal oxygen-dissociation properties. There is good evidence that the integrity of the sulfhydryl groups of hemoglobin is vital to the normal oxygen-dissociation characteristics of hemoglobin (58) and that these groups are involved in the degradation of hemoglobin by oxidants and by prolonged stasis $(28,30,36)$. There is also evidence by Beutler and his associates (19, 27) that free intracellular thiols, chiefly glutathione, are oxidized or destroyed by oxidant drugs and are probably involved in the intracellular defense against these drugs. The work of Mills and Randall (11, 42, 59) indicates that GSH may protect hemoglobin from oxidation by serving as an oxidizable substrate in the presence of an enzyme, glutathione peroxidase. However, at least part of the protective effect of GSH is nonenzymatic and involves defense of the hemoglobin sulfhydryl groups (36). Finally, it has been shown that oxidation or blocking of red cell thiols is associated with increased membrane permeability (60) and with frank hemolysis in vitro (61-64). It may be, therefore, that thiol oxidation represents a central phenomenon which couples the destruction of hemoglobin with that of the red cell itself. Thus the red cells of "glutathione-unstable" subjects, and perhaps those of patients with spontaneous Heinz body $(65,66)$ or similar inclusion body $(67,68)$ anemias may undergo a form of spontaneous, premature senescence. Such a process may, or may not be sufficiently severe to cause anemia in the absence of drugs, and its morphologic recognition (e.g., the identification of inclusion bodies) might be possible only in the absence of the spleen. Recent evidence by Brewer, Tarlov, Kellermeyer and Alving (69) indicates 
that the red cell lifespan in "glutathione-unstable" Negroes is significantly shorter than normal even in the absence of drug ingestion. The pattern of increased destruction is consistent with accelerated red cell senescence.

Red cell senescence has many features in common with senescence in another relatively inactive tissue, the lens of the eye. Like red cells, the lens contains a rich supply of GSH which falls during senility (70). As in red cells senescence is associated with a proteinaceous precipitate, the incipient cataract (70); as in red cells this event is presaged by a fall in GSH levels (71); and as in red cells this sequence of events may develop through interference with the pentose phosphate pathway, as by galactose $(72,73)$, or through exposure to an oxidant drug known to cause Heinz body anemias, naphthoquinone (74).

The observations here reported emphasize the fact that for its survival the red cell and its vital constituent, hemoglobin, are dependent upon certain special mechanisms for their common defense against the great oxidative potential of the very substance they are designed to transportmolecular oxygen. One of the seemingly essential features of this arangement is that there be a metabolic hiatus between oxygen and the cellular constituents, with an electron exchange sufficient only to provide the energy for certain necessary functions, including generation of $\mathrm{TPNH}$ for the reduction of glutathione. When this hiatus is bridged by the entrance of a redox intermediate into the red cell, when the cell's TPN-reducing apparatus has failed, or especially when both conditions coincide, the oxidative destruction of the cell is ordained.

\section{SUMMARY}

Phenylhydrazine and related redox compounds which cause Heinz body anemias in vivo were studied as to their effects in vitro on red cells and on solutions of crystalline human hemoglobin. With both substrates the following sequence of changes in hemoglobin were observed: 1) methemoglobin was formed until a new, hemoglobin $\rightleftharpoons$ methemoglobin equilibrium was achieved; 2) a fast-moving component of hemoglobin on electrophoresis and resin column chromatography appeared ; 3) a group of soluble, poorly soluble, and insoluble brown to green "sulfhemoglobin-like," denatured pigments appeared;4) these denatured products of hemoglobin precipitated into coccoid bodies ranging up to 2 or $3 \mu$ in diameter with properties identical to those of Heinz bodies. It is concluded that Heinz bodies represent granules of precipitated hemoglobin.

Drugs and chemicals active in this respect have the property of reacting with molecular oxygen, probably to form oxidant intermediates or free radicals capable of oxidizing hemoglobin and other intracellular components. These drugs thereby transmit the high oxidation potential of oxygen to cellular components in a cell containing uniquely high concentrations of oxygen and a substance, hemoglobin, which catalyzes the activation of the drug. In the course of several days red cells or hemoglobin incubated under oxygen alone underwent the same changes, including Heinz body formation, as those which occurred in minutes or hours in the presence of the oxidlant clrugs. Since some of these changes have been iclentified with aging in vivo, it appears that senescence, in the red cell at least, involves the irreversible oxidation of hemoglobin and of other cellular constituents. The Heinz body anemias appear to represent an acceleration of the normal processes of red cell aging.

\section{REFERENCES}

1. Webster, S. H. Heinz body phenomenon in erythrocytes. A review. Blood 1949, 4, 479.

2. Fertman, M. H., and Fertman, M. B. Toxic anemias and Heinz bodies. Medicine (Baltimore) 1955, 34, 131.

3. Lemberg, R., and Legge, J. W. Hematin Compounds and Bile Pigments; Their Constitution, Metabolism, and Function. New York, Interscience Publishers, 1949.

4. Dacie, J. V. The Haemolytic Anaemias; Congenital and Acquired. New York, Grune \& Stratton, 1954

5. Hughes, J. P., and Treon, J. F. Erythrocyte inclusion bodies in the blood of chemical workers. Arch. indust. Hyg. 1954, 10; 192.

6. Greenberg, M. S. Method for measuring mechanical fragility of $\operatorname{dog}$ red cells. Proc. Soc. exp. Biol. (N. Y.) 1955, 89, 320.

7. Kiese, M. Darstellung und Eigenschaften von Verdoglobinen. III. Mitteilung. Über die prosthetische Gruppe des Verdoglobins S (Sulfhämoglobins). Naunyn-Schmeideberg's Archiv exp. Path. Pharmak. 1948, 205, 747.

8. Beaven, G. H., and White, J. C. Oxidation of phenylhydrazines in the presence of oxyhaemoglobin and the origin of Heinz bodies in erythrocytes. Nature (Lond.) 1954, 173, 389. 
9. Kiese, M., and Kaeske, H. Verbindungen des Muskelhämoglobins. Biochem. Z. 1942, 312, 121.

10. Kiese, M., and Seipelt, L. Bildung und Elimination von Verdoglobin. Naunyn-Schmeideberg's Archiv exp. Path. Pharmak. 1943, 200, 648.

11. Mills, G. C., and Randall, H. P. Hemoglobin catabolism. II. The protection of hemoglobin from oxidative breakdown in the intact erythrocyte. J. biol. Chem. 1958, 232, 589.

12. Horecker, B. $\dot{L}$. Production of methemoglobin and denatured globin in dogs poisoned with T. N. T. in Public Health Bull. No. 285, U.S.P.H.S., Washington, D. C., 1944, p. 46.

13. Jung, F. Über Heinz-Körperchen. Klin. Wschr. 1943, 22, 42.

14. Rozsa, G., and Spicer, S. S. Nature of Heinz bodies. Nature (Lond.) 1953, 171, 84.

15. Emerson, C. P., Ham, T. H., and Castle, W. B. Hemolytic action of certain organic oxidants derived from sulfanilamide, phenylhydrazine and hydroquinone (abstract). J. clin. Invest. 1941, 20, 451.

16. Cruz, W. O. Acetylphenylhydrazine anemia. I. The mechanism of erythrocyte destruction and regeneration. Amer. J. med. Sci. 1941, 202, 781.

17. Emerson, C. P., Jr., Castle, W. B., and Ham, T. H. Unpublished data.

18. Beutler, E., Dern, R. J., and Alving, A. S. The hemolytic effect of primaquine. IV. The relationship of cell age to hemolysis. J. Lab. clin. Med. 1954, 44, 439.

19. Beutler, E. The hemolytic effect of primaquine and related compounds: A review. Blood 1959, 14, 103.

20. Carson, P. E., Flanagan, C. L., Ickes, C. E., and Alving, A. S. Enzymatic deficiency in primaquinesensitive erythrocytes. Science 1956, 124, 484.

21. Kiese, M. Die Reduktion des Hämiglobins. Biochem. Z. 1944, 316, 264.

22. Huennekens, F. M., and Gabrio, B. W. Methemoglobin reductase. Fed. Proc. 1954, 13, 232.

23. Conn, E. E., and Vennesland, B. Glutathione reductase of wheat germ. J. biol. Chem. 1951, 192, 17.

24. Rall, T. W., and Lehninger, A. L. Glutathione reductase of animal tissues. J. biol. Chem. 1952, 194, 119.

25. Marks, P. A., Johnson, A. B., Hirshberg, E., and Banks, J. Studies on the mechanism of aging of human red blood cells. Ann. N. Y. Acad. Sci. 1958, 75, 95.

26. Flanagan, C. L., Schrier, S. L., Carson, P. E., and Alving, A. S. The hemolytic effect of primaquine. VIII. The effect of drug administration on parameters of primaquine sensitivity. J. Lab. clin. Med. 1958, 51, 600.

27. Beutler, E., Robson, M., and Buttenwieser, E. The mechanism of glutathione destruction and protection in drug-sensitive and non-sensitive eryth- rocytes. In zitro studies. J. clin. Invest. 1957, $36,617$.

28. Jandl, J. H., and Allen, D. W. Oxidative hemolysis and precipitation of hemoglobin: Heinz body anemias as an accelerated form of red cell aging (abstract). J. clin. Invest. 1960, 39, 1000.

29. Drabkin, D. L. A simplified technique for a large scale crystallization of human oxyhemoglobin. Isomorphous transformations of hemoglobin and myoglobin in the crystalline state. Arch. Biochem. 1949, 21, 224.

30. Allen, D. W., Schroeder, W. A., and Balog, J. Observations on the chromatographic heterogeneity of normal adult and fetal human hemoglobin: A study of the effects of crystallization and chromatography on the heterogeneity and isoleucine content. J. Amer. chem. Soc. 1958, 80, 1628.

31. Evelyn, K. A., and Malloy, H. T. Microdetermination of oxyhemoglobin, methemoglobin, and sulfhemoglobin in a single sample of blood. J. biol. Chem. 1938, 126, 655.

32. Smith, E. W., and Conley, C. L. Filter paper electrophoresis of human hemoglobins with special reference to the incidence and clinical significance of hemoglobin C. Bull. Johns Hopk. Hosp. 1953, 93, 94.

33. Rosenfeld, M., and Surgenor, D. M. Methemalbumin. Interaction between human serum albumin and ferriprotoporphyrin IX. J. biol. Chem. 1950, 183, 663.

34. Rossi-Fanelli, A., Antonini, E., and Caputo, A. Pure native globin from human hemoglobin: Preparation and some physical-chemical properties. Biochim. biophys. Acta 1958, 28, 221.

35. Kunkel, H. G., and Wallenius, G. New hemoglobin in normal adult blood. Science 1955, 122, 288.

36. Allen, D. W., and Jandl, J. H. Oxidative hemolysis and precipitation of hemoglobin. II. Role of thiols in oxidant drug action. In preparation.

37. Mirsky, A. E., and Anson, M. L. Sulfhydryl and disulfide groups of proteins. III. Sulfhydryl groups of native proteins-Hemoglobin and the proteins of the crystalline lens. J. gen. Physiol. 1936, 19, 439.

38. Emerson, C. P., Ham, T. H., and Castle, W. B. The influence of resonating organic compounds on the integrity of red cells in Conference on the Preservation of the Formed Elements and of the Proteins of the Blood, Washington, D. C., published by the American National Red Cross, 1949, p. 114.

39. Bodansky, O. Methemoglobinemia and methemoglobin-producing compounds. Pharmacol. Rev. 1951, 3, 144.

40. Warburg, O., Kubowitz, F., and Christian, W. Über die Wirkung von Phenylhydrazin und Phenylhydroxylamin auf den Stoff wechsel der roten Blutzellen. Biochem. Z. 1931, 242, 170.

41. Heubner, W. Methämoglobin Innenkörper der Erythrocyten und Anämie. Klin. Wschr. 1941, 20, 137. 
42. Mills, G. C. The purification and properties of glutathione peroxidasc of erythrocytes. J. biol. Chem. 1959, 234, 502.

43. Jandl, J. H., Greenberg, M. S., Yonemoto, R. H., and Castle, W. B. Clinical determination of the sites of red cell sequestration in hemolytic anemias. $\mathrm{J}$. clin. Invest. 1956, 35, 842.

44. Ranney, H. M., and Kono, P. Studies of the incorporation of $\mathrm{Fe}^{59}$ into normal and abnormal hemoglobins. J. clin. Invest. 1959, 38, 508.

45. Putnam, F. W. Protein denaturation in The Proteins, H. Neurath and K. Bailey Eds. New York, Academic Press, 1953, vol. 1, part B, p. 807.

46. Merlini, D. Sopra la natura ed il significato dei corpi di Heinz. Omnia med. (Pisa) 1952, 30, 251.

47. Keilin, D., and Hartree, E. F. Reactions of haemoglobin and its derivatives with phenyl hydroxylamine and nitrosobenzene. Nature (Lond.) 1943, $151,390$.

48. Michaelis, L. Semiquinones, the intermediate steps of reversible organic oxidation-reduction. Chem. Rev. 1935, 16, 243.

49. Bingold, K. Die Niere als blutzerstörendes Organ. Klin. Wschr. 1933, 12, 1201.

50. Pepper, O. H. P. Vitally stainable reticulation and chromatic granules in erythrocytes preserved in vitro. J. Amer. med. Ass. 1922, 78, 1840.

51. Heath, C. W., and Daland, G. A. The life of reticulocytes. Experiments on their maturation. Arch. intern. Med. 1930, 46, 533.

52. Moeschlin, S. Versuche über die Entstehung von Innenkörpern in Erythrocyten (Heinzsche Körperchen) in vivo und vitro durch Sulfanilamid Derivate und Phenylhydrazin. Folia haemat. (Lpz.) 1941, 65, 345.

53. Case, R. A. M. Siderocytes in mammalian blood. Nature (Lond.) 1943, 152, 599.

54. Schilling, V. Erweiterte hämotologische Verwertung des “dicken Bluttropfens" für Kernkugeln, Innenkörper, Endothelien u. a. Dtsch. med. Wschr. 1921, 47, 825.

55. Zadek, I., and Burg, K. Innenkörperanämien. Folia haemat. (Lpz.) 1930, 41, 333.

56. Selwyn, J. G. Heinz bodies in red cells after splenectomy and after phenacetin administration. Brit. J. Haemat. 1955, 1, 173.

57. Gasser, C., and Willi, H. Spontane Innenkörperbildung bei Milzagenesie. Helv. paediat. Acta 1952, 7, 369.

58. Riggs, A. F., and Wolbach, R. A. Sulfhydryl groups and structure of hemoglobin. J. gen. Physiol. 1956, 39, 585.
59. Mills, G. C. Hemoglobin catabolism. I. Gilutathione peroxidase, an erythrocyte enzyme which protects hemoglobin from oxidative breakdown. J. biol. Chem. 1957, 229, 189.

60. Ørskov, S. L. Untersuchungen über den Einfluss von Kohlensäure und Blei auf die Permeabilität der Blutkörperchen für Kalium und Rubidium. Biochem. Z. 1935, 279, 250.

61. Keilin, D., and Hartree, E. F. Spectroscopic study of permeability and lysis of red blood corpuscles. Nature (Lond.) 1946, 157, 210.

62. Fegler, G. Relationship between reduced glutathione content and spontaneous haemolysis in shed blood. Nature (Lond.) 1952, 170, 624.

63. Benesch, R. E., and Benesch, R. Relation between erythrocyte integrity and sulfhydryl groups. Arch. Biochem. 1954, 48, 38.

64. Sheets, R. F., and Hamilton, H. E. A reversible effect on the metabolism of human erythrocytes by p-chloromercuribenzoic acid and N-ethyl maleimide. J. Lab. clin. Med. 1958, 52, 138.

65. Rohr, K. Das menschliche Knochenmark; seine Anatomie, Physiologie und Pathologie nach Ergebnissen der Intravitalen Markpunktion. 2. Aufl. Stuttgart, G. Thieme Verlag, 1949.

66. Cathie, I. A. B. Apparent idiopathic Heinz body anaemia. Gt Ormond Str. J. 1952, 3, 43.

67. Lange, R. D., and Akeroyd, J. H. Congenital hemolytic anemia with abnormal pigment metabolism and red cell inclusion bodies: A new clinical syndrome. Blood 1958, 13, 950.

68. Schmid, R., Brecher, G., and Clemens, T. Familial hemolytic anemia with erythrocyte inclusion bodies and a defect in pigment metabolism. Blood 1959, 14, 991.

69. Brewer, G. J., Tarlov, A. R., Kellermeyer, R. W., and Alving, A. S. Shortened eythrocyte life span in primaquine sensitive male Negroes in the absence of drug administration. In preparation.

70. Dische, Z., and Zil, H. Studies on the oxidation of cysteine to cystine in lens proteins during cataract formation. Amer. J. Ophthal. 1951, 34, 104.

71. Pirie, A., Van Heyningen, R., and Boag, J. W. Changes in lens during the formation of $x$-ray cataract in rabbits. Biochem. J. 1953, 54, 682.

72. Bellows, J. G., and Rosner, L. Studies on galactose cataract. Amer. J. Ophthal. 1937, 20, 1109.

73. Lerman, S. Enzymatic factors in experimental galactose cataract. Science 1959, 130, 1473.

74. May, C. H. May's Manual of the Diseases of the Eye, 19th ed., C. A. Perera, Ed. Baltimore, Williams \& Wilkins Co., 1947. 